\title{
A CERTIFICAÇÃO FAIRTRADE NO SETOR EXPORTADOR DE FRUTAS FRESCAS NO BRASIL
}

\author{
Fairtrade Certification in the Fresh Fruit Export Sector in Brazil
}

\begin{abstract}
RESUMO
No Brasil, a certificação Fairtrade é aplicada em diversos produtos; contudo, um dos que mais se destaca é o segmento de frutas frescas. Foi utilizada a Economia dos Custos de Transação (ECT) com o intuito de identificar e analisar os contratos existentes na rede Fairtrade de Frutas Frescas Brasileiras, bem como verificar o tipo de estrutura de governança da rede. O método adotado foi o estudo de caso. Iniciou-se pela pesquisa bibliográfica sobre a rede Fairtrade e a ECT. Em seguida, realizou-se a pesquisa documental por meio dos contratos e normas de produção e comercialização, disponibilizados pelas organizações produtoras e nos sites da Fairtrade International e Flo-Cert. Além disso, entrevistas semiestruturadas foram realizadas junto aos agentes envolvidos na referida rede. As análises identificaram que a governança na rede é do tipo híbrida e que a Fairtrade International atua como centro estratégico e possui a responsabilidade de coordenar toda a rede. Também foram identificados três tipos de contratos envolvendo as organizações produtoras (OPs), os quais ligam as OPs à rede Fairtrade, aos traders, e aos seus importadores. A relação que surge nas transações contratuais na rede é de dependência trilateral e os contratos são do tipo neoclássico, com frequência discreta. $\mathrm{O}$ estado do conhecimento atingido a partir dos contratos analisados pode ser utilizado em outros estudos, com impacto sobre a identificação se há um fortalecimento ou enfraquecimento das relações contratuais entre os agentes envolvidos na rede Fairtrade.
\end{abstract}

Rosemary Barbosa de Melo

Instituto Federal do Sertão Pernambucano

rosemary.barbosa@ifsertao-pe.edu.br

Jean Philippe Palma Revillion

Universidade Federal do Rio Grande do Sul

jeanppr@gmail.com

Leonardo Xavier da Silva

Universidade Federal do Rio Grande do Sul

leonardo.xavier@ufrgs.br

Recebido em: 25/02/2020

Aprovado em: 01/12/2020

Avaliado pelo sistema double blind review

Avaliador científico: Eduardo César Silva

DOI: $10.48142 / 2220201587$

\begin{abstract}
In Brazil, Fairtrade certification is applied to several products; however, one of the most outstanding is the fresh fruit segment. Transaction Cost Economics (ECT) was used in order to identify and analyze the existing contracts in the Fairtrade network of Brazilian Fresh Fruits, as well as to verify the type of governance structure of the network. The method adopted was the case study. It started with bibliographic research on the Fairtrade network and ECT. Then, the documentary research was carried out through the production and commercialization contracts and standards, made available by the production organizations and on the websites of Fairtrade International and Flo-Cert. In addition, semi-structured interviews were conducted with the agents involved in that network. The analyzes identified that the governance in the network is of the hybrid type and that Fairtrade International acts as a strategic center and has the responsibility to coordinate the entire network. Three types of contracts were also identified involving producer organizations (OPs), which link OPs to the Fairtrade network, traders, and their importers. The relationship that arises in contractual transactions on the network is trilateral and the contracts are of the neoclassical type, with discrete frequency. The state of knowledge reached from the analyzed contracts can be used in other studies, with an impact on the identification if there is a strengthening or weakening of the contractual relations between the agents involved in the Fairtrade network.
\end{abstract}

Palavras-chave: Fruticultura; Comércio Internacional; Economia de Custos de Transação; Contratos.

Keywords: Fruit growing; International Trade; Transaction Cost Economics; Contracts.

Organizações Rurais \& Agroindustriais, Lavras, 22:e1587, 2020 


\section{INTRODUÇÃO}

Para o agronegócio brasileiro, a fruticultura possui um lugar de destaque, pois o país é o terceiro maior produtor mundial de frutas, o que corresponde a 5,3\% da produção total mundial (FAO, 2012). O país só é superado pela China e pela Índia, mas, em relação à produção de frutas tropicais, possui a liderança (FAO, 2012).

A União Europeia (UE) é um grande importador mundial de frutas e o maior comprador de frutas brasileiras. De 2017 a 2019, importou 445 milhões de quilogramas de frutas, registrando um valor de aproximadamente US\$ 513 milhões (BRASIL, 2020).

As frutas que são exportadas para UE, além de serem comercializadas por meio do comércio convencional, também são escoadas por meio de um comércio alternativo denominado de Fairtrade. Essa certificação internacional tem como objetivo principal combater a pobreza por meio da execução das políticas capazes de atingir os países em desenvolvimento e por meio de relações de troca mais justas com os países desenvolvidos. Um dos instrumentos adotados pela rede é o prêmio, este corresponde a um adicional, em dinheiro, pago aos agricultores e trabalhadores com o objetivo de melhorarem as suas condições sociais, econômicas e ambientais, bem como das suas famílias e da comunidade local.

Esta pesquisa se interessa pelos mecanismos de cooperação e coordenação de produtores certificados por sistemas de caráter socioambiental e desses com as instituições de certificação e comercialização. $\mathrm{O}$ relacionamento cooperativo, em muitos casos, depende da estabilidade da relação o que é, muitas vezes, influenciado pelo tipo de coordenação do arranjo (GRASSI, 2004). Destaca-se que a certificação Fairtrade tem como prérequisito a organização dos pequenos produtores e trabalhadores de empresas agrícolas, em associações ou cooperativas, de maneira a viabilizar o procedimento (KUHLMANN, 2006).

Um dos instrumentos que contribuem na coordenação desse tipo de arranjo organizacional são os contratos, os quais permitem que as partes envolvidas compartilhem riscos e forneçam incentivos para cooperação (COOK; KLEIN; ILIOPOULOS, 2008). No entanto, ressalta-se que, para a definição da estrutura de governança, é salutar identificar, nas relações contratuais entre os agentes econômicos, quais os contratos existentes nas transações e, além disso, identificar qual o tipo de contrato. Assim, o presente estudo tem como objetivo identificar quais os contratos existentes na rede Fairtrade Frutas Frescas Brasileiras, bem como a estrutura de governança que a norteia.

\section{REVISÃO DA LITERATURA}

\subsection{Economia dos Custos de Transação (ECT)}

O embasamento teórico da ECT iniciou-se com a obra de Ronald Coase "The Nature of the Firm", que investigou a razão da existência das firmas. Posteriormente, com as ideias de Coase foram surgindo novos trabalhos. O que mais se destacou foi o desenvolvido por Williamson (1989), que, no desenvolvimento da ECT, ampliou a discussão sobre custo de transação em termos teóricos e analíticos, ressaltando que há entre os agentes, uma interação e compromissos intertemporais em um contexto jurídico. Também o autor destaca que, visando diminuir seus custos de transação, os agentes escolhem os arranjos verticais mais eficientes para um dado ambiente institucional.

A existência de custos de transação, nesse processo, incentiva o surgimento de instituições que preservem a continuidade da relação por meio de ajustes; caso necessário, para que não haja o rompimento de relações contratuais. Para Douglas North (1981), custos de transação são custos de se mensurar aquilo que é trocado por meio da execução dos contratos. Em sua trajetória intelectual, North reconhece a importância dos custos de transação para o entendimento da economia e da mudança institucional (CANDELA, 2018).

Também dois pressupostos comportamentais são essenciais para a compreensão da ECT: Racionalidade Limitada e Oportunismo (WILLIAMSON, 1993). A racionalidade limitada é um pressuposto que está em consonância com o comportamento otimizador, em que o agente econômico deseja otimizar, entretanto não consegue satisfazer tal desejo. No dizer de Simon (1962), os atores econômicos desejam ser racionais, mas apenas conseguem sê-lo de maneira limitada.

Quanto ao oportunismo, Williamson (1985, p. 30) o define como "condição da busca de auto interesse com astúcia" e resume comportamentos, como mentir, roubar, lograr, formas sutis de enganar, revelar informação de forma distorcida ou incompleta, ofuscar, confundir, etc. $\mathrm{O}$ autor menciona, ainda, que não são todas as pessoas que se comportam de maneira oportunista o tempo todo, mas algumas, em algumas vezes. Além disso, o oportunismo favorece a incerteza, pois leva os agentes econômicos 
à incerteza de que elementos acordados entre as partes possam não ser efetivados (AZEVEDO, 1997).

A racionalidade limitada e o oportunismo contribuem para os riscos das transações, afetando o cumprimento destas de acordo com o que foi planejado (WILLIAMSON, 1991). Assim, quanto maior for o nível de oportunismo constatado no padrão comportamental dos agentes e quanto menos informações estiverem disponíveis para a tomada de decisão, mais o risco torna-se um impulsionador de custos de transação (WILLIAMSON, 1991). Os custos de transação são oriundos de transações ineficientes de determinada organização com o mercado de atuação (BALESTRIN; ARBAGE, 2007).

A assimetria informacional caracterizase quando nem todos os fatos são conhecidos por ambas as partes contratantes, situação essa em que a informação é tida como incompleta (HENDRIKSEN; VAN BREDA, 1999).

Além disso, as relações contratuais caracterizamse, em termos de transações, por três elementos: frequência, incerteza e especificidade dos ativos. Essas, por sua vez, são consideradas como dimensões pela ECT e configuram uma tentativa de selecionar o melhor arranjo organizacional. Tais dimensões acarretam distintos custos de transação e formas organizacionais (AZEVEDO, 1997). De acordo com Silva (2002), a frequência pode ser ocasional (não há compromisso entre os agentes), discreta (estabelece-se contrato supervisionado até o seu final) e recorrente (transação contínua, com forte coordenação e inter-relação entre os agentes da estrutura produtiva).

As incertezas são contingências que são difíceis ou impossíveis de prever e que geram problemas de adaptação (JOHN; WEITZ, 1988). É decorrente da incapacidade em se prever integralmente as atitudes dos agentes econômicos e as mudanças no ambiente, de forma a não permitir que se estabeleça um contrato que contemple contingências futuras (MELLO; PAULILLO, 2009).

De acordo com Azevedo (1997), a frequência consiste no número de vezes ou repetições das transações realizadas. Transações frequentes representam um indicador de confiança entre as partes envolvidas na barganha. Quanto maior for a frequência, menores serão os custos fixos médios associados à coleta de informações e à elaboração de um contrato complexo que imponha restrições ao comportamento oportunista.

As especificidades dos ativos são oriundas de distintas fontes/situações, dentre as quais Williamson (1996) destaca: i) especificidade locacional: quando as decisões de localização de ativos nas proximidades de outras de uma mesma cadeia produtiva visam minimizar despesas com estoques e transporte, significando retornos específicos a essas unidades específicas; ii) especificidade física: refere-se aos ativos envolvidos na produção do bem; iii) especificidade de capital humano: diz respeito ao conhecimento fundamentado dos recursos humanos da empresa envolvidos direta ou indiretamente na transação e de sua capacidade de aprender e executar uma função específica; iv) especificidade de ativos dedicados: refere-se aos casos em que um fornecedor precisa fazer investimentos que não são intrinsecamente específicos, mas que foram realizados para suprir a demanda de um cliente específico, sendo, portanto, a ele dedicados; v) especificidade de marca: trata-se de um ativo intangível cujo retorno se materializa, marca, nome e/ou reputação de uma empresa, num mercado em particular; vi) especificidade de ativos temporais: refere-se ao tempo para efetivação de transações, em que o seu valor de retorno depende, sobretudo, do tempo em que ela se processa.

Em suma, os contratos envolvem custos devido à assimetria de informações, à racionalidade limitada, à complexidade e à incerteza do ambiente, ao oportunismo e à baixa especificidade de ativos e à baixa frequência das transações. Esse conjunto de fatores torna os custos de transação significativos, tornando sua análise fundamental na tentativa de minimizá-los (ZYLBERSZTAJN, 2000). De acordo com Carvalho (2015), a assimetria informacional associada ao risco moral contribui para a necessidade de uma coordenação eficiente e que apresente garantias de reputação.

\subsection{Estruturas de Governança: Escolha da Forma de Coordenação das Relações Contratuais}

Devido à incompletude dos contratos, faz-se necessário que os agentes econômicos construam estruturas de governança. Essa, por sua vez, é definida como “(...) a matriz institucional dentro da qual as transações são negociadas e executadas" (WILLIAMSON, 1986, p. 105).

Vale ressaltar que as obrigações contratuais podem ser elaboradas, concluídas e exercidas sob diversos desenhos institucionais; por isso, é necessário que se criem estruturas de governança que deem conta das necessidades de ajustes ex post aos termos da transação, à medida que circunstâncias imprevistas forem surgindo (FIANI, 2013).

Assim, visando contribuir com o cumprimento dos contratos, de modo eficiente, define-se uma estrutura de governança, que melhor minimize os custos de transação a partir da melhor alocação de recursos. Essa, por sua vez, incide sobre os contratos com o intuito de facilitar 
as trocas de produtos ou serviços entre os agentes econômicos (SANTOS, 2010). Logo, a estrutura de governança é determinada para inibir o comportamento oportunista por uma ou mais partes envolvidas em uma transação.

Foi desenvolvido por Williamson (1993, p.112) um esquema de três níveis em que o ambiente institucional, estrutura de governança e indivíduos interagem, estabelecendo relações de influência mútua. O modelo privilegia, no seu foco de análise, a estrutura de governança, e serve como um importante ponto de referência ao estudo das inter-relações entre os diferentes níveis analíticos. $\mathrm{O}$ ambiente institucional provê as regras que norteiam o aparecimento e a seleção de formas organizacionais que irão compor a estrutura de governança (AZEVEDO, 1997).

A intensidade de coordenação entre os agentes localizados em diferentes estágios de uma cadeia produtiva pode ocorrer em diversos níveis, que vão desde a transação de mercados livres, passando por contratos de curto prazo a contratos de longo prazo até chegar à integração vertical de uma firma a outra. Os ajustes ex post são os arranjos institucionais (estrutura de governança) alternativos ao mercado, que Williamson denominou, de forma genérica, hierarquia e híbridos (FIANI, 2013). Essa classificação tem como referência os três tipos de contratos de Macneil (1978): clássicos, neoclássicos e relacionais.

Evidencia-se que Williamson desenvolveu as premissas da ECT e, para isso, ele considerou os três tipos de contratos do Direito nas suas análises (WILLIAMSON, 1979):

1. Contrato clássico: Os ajustes ocorrem apenas via mercado, ou seja, não há planejamento de longo prazo e onde a barganha se esgota nas negociações de preços. Novas transações discretas são definidas por meio de acordos, e o desempenho dessas será obtido mediante as adaptações necessárias. A principal característica do contrato clássico é que ele busca intensificar as características discretas e a presenteação. As regras legais, documentos e a transação autoliquidável são elementos indispensáveis nesse tipo de contrato.

2. Contrato neoclássico: São os contratos de longa duração e por tempo determinado, que reconhecendo a complexidade dos negócios e o fato de os acordos serem incompletos, ao menos que ambas as partes tenham confiança em um acordo, a tendência é que os acordos não sejam cumpridos. No entanto, a principal característica desse tipo de contrato é a manutenção do contrato original nas renegociações. Esses tipos de contratos são executados em condição de incerteza e em que as adaptações devem ser negociadas (NICOLAU, 1994).

3. Contrato relacional: A flexibilidade e a possibilidade de renegociação são características marcantes dos contratos relacionais. Outro aspecto que o define é que o contrato original pode não ser referência para ajustes contratuais decorrentes da sua longa duração e complexidade. Assim, diferentemente dos contratos neoclássicos, em que o acordo original é referência para ajustes, nos contratos relacionais, não considera em cada negociação todas as cláusulas para a reconstrução do contrato. Outra característica que o distingue do neoclássico é a troca do esforço de desenhar um contrato completo pelo esforço de manter uma negociação continuada e por tempo indeterminado.

Além disso, Williamson $(1985,2012)$ os associa às características das transações, em especial à especificidade dos ativos e às estruturas de governança, nos termos seguintes:

a) Estrutura de mercado: é a principal estrutura de governança para transações não específicas de contratação ocasional e recorrente. Os mercados são eficazes em transações recorrentes, uma vez que ambas as partes precisam apenas decidir se devem continuar na relação ou não, tomando como base as suas próprias experiências, isso com um baixo custo de transação. Assim, os mercados correspondem a um contrato clássico, pois a transação é resolvida em um ponto do tempo, não existindo compromisso com acordos futuros. Nesse caso, compradores e vendedores não estão envolvidos em uma relação de dependência, sendo o preço estabelecido por competição de mercado. Esse tipo de governança é caracterizado pelo baixo grau de especificidade de ativos, independentemente da frequência da transação. Na governança de mercado, o comprador tem condições de escolher o seu fornecedor, selecionando aquele que apresentar os melhores atrativos. Desse modo, não existe qualquer vínculo entre comprador e vendedor (FIANI, 2013). À luz do que foi exposto, os incentivos têm uma elevada importância, pois são os ganhos e as perdas monetárias dos agentes no mercado que determinam suas decisões (FIANI, 2013). O autor, ainda, ressalta que o mercado promove o que é chamado adaptação autônoma, que ocorre quando cada agente busca, individualmente e de forma unilateral, a melhor resposta para a mudança no ambiente de transação. 
b) Estrutura híbrida: partes das transações são autônomas, havendo, porém, certo grau de dependência bilateral; são norteadas por contratos ou acordos com diversos tipos de complexidade. Portanto, apresentam atributos distintos de mercado e hierarquia, por lidarem com a dependência bilateral, em que a autonomia das partes é mantida, mas sem atingir o nível de integração vertical (WILLIAMSON, 1996, 2012). A governança híbrida ocorre em meio à presença de ativos mistos, alguns específicos e outros não. Tomando como base a frequência da transação, se ela for recorrente, a governança é tida como relacional bilateral, sob frequência única ou ocasional, mas, se for por tempo determinado, envolvendo as duas partes contratantes, mais uma parte responsável pelo controle e pela arbitragem, a governança é considerada trilateral (CARIO; NICOLAU, 2012). Fazendo uma comparação entre a híbrida e os demais tipos de governança, apresenta diferenças relevantes, no que tange ao aspecto de incentivos e à cooperação. Pois "quando comparada com o mercado, sacrifica incentivos em benefício de uma coordenação superior entre as partes" (GRASSI, 2003, p.46). A governança híbrida combina os incentivos e controles administrativos, de forma que há elementos que se aproximam do mercado e outros da hierarquia (FIANI, 2013). $\mathrm{O}$ autor, ainda, ressalta que os agentes, mesmo submetidos a controles definidos previamente na estrutura institucional, a independência de cada um é preservada. Para Ménard (2011), um fator que determina a governança híbrida é a presença de uma entidade que domina e coordena as relações contratuais interfirmas. Os centros estratégicos podem ser entendidos como uma expressão abreviada para entidades institucionais, que comandam e controlam as transações, no que diz respeito a sua inicialização, negociação, a seu monitoramento e também a sua finalização. É nesses centros que são elaboradas e coordenadas as ações coletivas e onde se monitoram os direitos de decisão conjunta.

c) Estrutura hierárquica: também conhecida como integração vertical, corresponde à incorporação da transação para dentro dos domínios da firma, ou seja, na total internalização das atividades por uma única empresa, por meio da propriedade integral dos ativos (SANTOS, 2010), limitando, assim, a possibilidade de comportamento oportunista. Nesse tipo de estrutura, o fluxo de caixa e o controle dos materiais são direcionados para o nível mais alto do gerenciamento hierárquico. Há um gerenciamento hierárquico entre o fornecedor e o comprador (GROVER; MALHOTRA, 2003). Por fim, esse tipo de governança é adequado na presença de elevada especificidade e com frequência recorrente. O modo de adaptação, nesse tipo de estrutura, é a coordenada, pois os agentes envolvidos são coordenados por controles administrativos, devido às mudanças no ambiente da transação, ou seja, pelos comandos exercidos por agentes com autoridade para isso definida hierarquicamente (WILLIAMSON, 1996; FIANI, 2013).

À luz do que foi exposto, Zylbersztajn (1995) sugere que, além das dimensões especificidade dos ativos, frequência e incerteza, essas já discutidas anteriormente, com referência às transações, sejam introduzidas mais três dimensões, estas associadas ao padrão dos contratos, adaptabilidade, incentivos e controles, conforme apresentadas a seguir (2010, p. 78): a) as formas de mercado possuem um alto grau de incentivo para os agentes envolvidos na transação; no entanto, a capacidade de adaptação não é tão eficiente quanto numa estrutura verticalizada, isso devido ao ambiente turbulento. Assim, os elevados incentivos devem ser acompanhados de reduzida adaptabilidade; b) já nas formas híbridas de governança a autonomia é preservada sem comprometer os incentivos. Quanto aos custos administrativos, podem situar-se em um nível intermediário entre o mercado e o da solução interna e, c) nas estruturas verticalizadas, os incentivos são excluídos, enquanto que os controles internos são mais elevados. No entanto, a flexibilidade é ampliada para executar as adaptações.

\section{PROCEDIMENTOS METODOLÓGICOS}

O método de pesquisa adotado é o de estudo de caso. Esse método se propõe a investigar um fenômeno contemporâneo dentro do seu contexto real, em que os limites entre os mesmos não são claramente percebidos, tornando o estudo de caso uma investigação empírica (YIN, 2005). Tem como objeto de estudo a rede Fairtrade de Frutas Frescas Brasileiras. O trabalho desenvolvido possui uma abordagem qualitativa. Quanto ao caráter, a pesquisa é bibliográfica, documental e de campo.

Inicialmente, foi realizada a pesquisa bibliográfica sobre a rede Fairtrade e a Economia dos Custos de Transação. 
Em seguida, realizou-se pesquisa documental por meio dos contratos e normas de produção e comercialização, disponibilizados pelas organizações produtoras e nos sites da Fairtrade International e Flo-Cert. Além disso, entrevistas semiestruturadas foram realizadas junto aos agentes envolvidos na rede Fairtrade de Frutas Frescas Brasileiras. Estas foram feitas via telefone, apenas três foram presenciais, no caso, a Cooperativa de Citricultores Ecológicos do Vale do Caí LTDA (ECOCITRUS), Associação dos Pequenos Produtores do Perímetro Irrigado de Maniçoba (MANGA BRASIL) e Associação dos Produtores Rurais do Núcleo VI.

Participaram das entrevistas um representante de cada organização produtora, no total de 13(treze) entrevistados e 14(quatorze) representantes das organizações, que também fazem parte da referida rede, conforme apresentado abaixo. Todos os representantes, no período de realização das entrevistas, em 2014, faziam parte da equipe gestora das organizações que participaram dessa pesquisa.

Ressalta-se que fizeram parte da pesquisa todas as 13 (treze) organizações produtoras que faziam parte da lista Flo-Cert, no período de 2010 a 2015, sendo elas: ECOCITRUS, Cooperativa de Agricultura Familiar e Solidária do Paraná (COACIPAR), Cooperativa Agroindustrial (COCAMAR), Cooperativa Agroextrativista do Marajó (COPAVEM), Cooperativa dos Fruticultores da Agricultura Familiar do Estado do Rio Grande do Sul (COOFRUTAF), Cooperativa de Produtores de Frutas de Santa Maria (COOPERSANTA), Cooperativa de Desenvolvimento Agroindustrial Potiguar (COODAP), Pritam Frut e Exportação LTDA (PRITAM FRUT), Cooperativa dos Agropecuaristas Solidários de Itápolis (COAGROSOL), Associação dos Produtores Rurais do Núcleo VI, MANGABRASIL, Cooperativa dos Agricultores das Frutas da Paz (COOAPAZ) e Associação de Citricultores de Liberato Salzano.

De forma a complementar as informações prestadas pelas organizações produtoras, também, foram realizadas 14 (quatorze) entrevistas semiestruturadas junto às organizações que representam o ambiente institucional. Assim, também, foram contempladas nesta pesquisa: Fairtrade Labelling Organizations International (Fairtrade International), Coordinadora Latinoamericana y del Caribe de Comercio Justo (CLAC), Associação das Organizações e Produtores Fairtrade do Brasil (BRFAIR), Faces do Brasil, Companhia de Desenvolvimento do Vale do São Francisco (CODEVASF), Associação Brasileira de Comércio Justo (Fairtrade Brasil), Serviço Brasileiro de apoio às Micros e Pequenas Empresas (SEBRAE) e Secretaria Especial de Desenvolvimento Econômico Solidário (SEDES). Além dessas organizações, algumas que atuam como traders na rede Frutas Frescas também foram contempladas na pesquisa, tais como: BIO ECOBRAZIL e Ética Comércio Solidário. Ainda, especialistas de outras instituições, tais como a Associação dos Pequenos Produtores do Cerrado (APPCER) e Cooperativas Sin Fronteras contribuíram com o estudo.

As informações das entrevistas e documentos disponibilizados possibilitaram analisar as relações existentes entre os agentes da rede Fairtrade de Frutas Frescas Brasileiras sob a ótica da ECT. Para tratamento dos dados coletados, via entrevistas, foi utilizado o método de análise de conteúdo. Consideraram-se conceitos da assimetria informacional, oportunismo, frequência das transações, racionalidade limitada, frequência das transações. Esses permitiram identificar como os agentes se organizam e, assim, apresentar a estrutura de governança adotada pela rede.

\section{RESULTADOS E DISCUSSÃO}

Para entender como se dá a discussão acerca de custos de transação e os tipos de contratos existentes na rede Fairtrade de frutas frescas no Brasil, é importante mapear os agentes relevantes para as transações e algumas características peculiares da governança na rede.

\subsection{A rede Fairtrade no mundo e no Brasil}

A rede certificada Fairtrade visa atender às normas internacionais desde o processo de produção até a venda ao consumidor final, apresentando nos seus produtos uma rotulagem. Ambos os percursos se fazem por iniciativas privadas (FAIRTRADE INTERNATIONAL, 2009; BOUROULLEC, 2010).

A rede Fairtrade é consolidado mundialmente. Atualmente, é composta por mais de 1,7 milhão de produtores e trabalhadores, organizados em 1.707 organizações, isso em 73 países do mundo (FAIRTRADE INTERNATIONAL, 2019a). Destaca-se que 89\% dos produtores da rede Fairtrade são formados por pequenos produtores e os $11 \%$ restantes representam os trabalhadores de fazendas (FAIRTRADE INTERNATIONAL, 2019b).

Em 2018, os produtos Fairtrade foram comercializados em 158 países. Os produtores e trabalhadores receberam de prêmio $€ 176.5$ milhões. Estes recursos foram destinados, em sua maioria, ao combate à pobreza e à fome (FAIRTRADE INTERNATIONAL, 2019a). 
Diversos são os produtos comercializados com o selo Fairtrade, no Brasil, os quais são: o café, suco de laranja, uva de vinho, mel, polpa de manga e goiaba, soja, amendoim, castanha de caju, algodão e frutas frescas (laranja, limão, abacaxi, manga e maracujá). O café, o suco de laranja e as frutas frescas são os produtos mais comercializados na rede. Destaca-se que estudos acadêmicos sobre o café e o suco de laranja com certificação Fairtrade, no Brasil, já foram desenvolvidos; no entanto, sobre as frutas frescas no âmbito nacional, carece de uma maior atenção e é exatamente a isso que este estudo se propôs.

\subsection{Caracterização dos agentes da rede Fairtrade Frutas Frescas Brasileiras}

O sistema de certificação Fairtrade é coordenado pela Fairtrade International (FLO), uma associação sem fins lucrativos, fundada em 1997. Ela possui a marca Fairtrade, desenvolve e avalia as normas internacionais de certificação. Além disso, é responsável pela auditoria de produtos em toda a cadeia de suprimentos, desde o produtor, o comerciante até o produto final. A sua sede é em Bonn na Alemanha.

A estrutura organizacional da FLO é constituída por duas organizações: uma delas é a Fairtrade Labelling Organizations Internacional e V. ou FLO e. V. e a outra é a FLO-Cert. A primeira corresponde a uma associação beneficente cuja afiliação é aberta a organizações com território geográfico definido e que pretendam obter licença para o uso do selo Fairtrade. Essas organizações são chamadas de Iniciativas Nacionais de Certificação.

A FLO Certification of Economic and Social Development GmbH ou Flo- Cert. Ltda., uma entidade juridicamente independente e que executa os trabalhos de certificação Fairtrade.

Esta pesquisa considerou as organizações produtores que constam na lista Flo-Cert na categoria frutas frescas, no período de 2010 a 2015. A rede Fairtrade Frutas Frescas Brasileira possui os seguintes agentes envolvidos: organizações produtoras (organizações de pequenos produtores e fazendas), traders, importadores (compradores). No que tange às organizações de produtores, a pesquisa contemplou 13(treze) organizações, são elas: COACIPAR/PR, COCAMAR/PR, COPAVEM/ PA, COAGROSOL/SP, COOPERSANTA/PR, MANGA BRASIL/BA, ASSOCIAÇÃO DO NÚCLEO VI/PE, PRITAM FRUT/ BA, COODAP/RN, COOAPAZ/RN, ASSOCIAÇÃO DOS CITRICULTORES DE LIBERATO SALZANO/RS, ECOCITRUS/RS E COOFRUTAF/RS.
As frutas frescas com a certificação Fairtrade, no Brasil, são: açaí, abacaxi, laranja, manga, limão e melão. A quantidade de frutas comercializadas na rede não é muito significativa em comparação às exportações brasileiras de frutas pelo mercado convencional; no entanto, devem-se valorizar as iniciativas de certificações socioambientais, tendo em vista que há uma demanda crescente no mercado internacional, em especial, no europeu, que é o principal comprador das frutas brasileiras. Destacase que as organizações: ECOCITRUS, COACIPAR, COAGROSOL, COCAMAR, COOPERSANTA, Associação de Citricultores de Liberato Salzano e COOFRUTAF não exportam laranja in natura na rede Fairtrade e sim o suco; porém, elas são registradas em duas categorias a de frutas frescas e sucos. Mas, como elas estão aptas a comercializar frutas frescas pela rede Fairtrade, também, foram contempladas nesta pesquisa. Caso semelhante acontece com a COPAVEM, que está cadastrada para comercializar o açaí in natura e em polpa. Ressalta-se que, das (13) treze organizações produtoras apresentadas acima, apenas uma é classificada na rede Fairtrade como empresa agrícola, chamada pelo sistema de "fazenda", a PRITAM FRUT.

Existem organizações estratégicas que fazem parte da rede Frutas Frescas Brasileiras, uma delas é a Coordinadora Latinoamericana y del Caribe de Pequeños Productores de Comercio Justo, a qual é uma rede que representa todas as organizações certificadas "Fairtrade" da América Latina e do Caribe, assim como outras organizações de comércio justo, tem como função defender os interesses dos seus membros (CLAC, 2020). A sua ação tem proporcionado a constituição de outras organizações que visam ao fortalecimento do sistema Fairtrade no Brasil, como a Associação das Organizações de Produtores (BRFair) e Fairtrade do Brasil. Também, deve-se considerar a presença de outras organizações tidas, neste estudo, como essenciais na inserção e, em alguns casos, na permanência delas na rede, mesmo não fazendo parte, efetivamente, da estrutura organizacional da rede Fairtrade. Assim, podem-se destacar: o SEBRAE, CODEVASF, EMATER, SENAE, MDA, EMBRAPA e Prefeituras.

\subsection{Estrutura de Governança e os tipos de contratos existentes na rede Fairtrade Frutas Frescas Brasileiras}

\subsubsection{Estrutura de Governança}

Para a análise das estruturas de governança, de acordo com Williamson $(1985,2012)$, o grau dos 
incentivos deve ser considerado. Desse modo, quanto ao ingresso das 13 (treze) organizações produtoras de frutas frescas na rede Fairtrade, pode-se observar que há diferenças quanto aos incentivos e apoios organizacionais para a entrada. A maioria delas teve como incentivo de inserção o já envolvimento em programas de qualidade na produção, liderados por organizações governamentais e privadas, que sinalizaram à rede Fairtrade uma alternativa para o escoamento dos seus produtos. Assim, a rede Fairtrade se tornou um meio de ampliar os programas brasileiros de qualidade na produção, buscando inserir um meio de comercialização que desse continuidade aos princípios socioambientais dos programas. Esse quadro se configura mais nas organizações produtoras do Norte e Nordeste. Outros motivos que levaram algumas OPs a ingressarem na rede foram a possibilidade de ampliar seus negócios internacionais, por meio de obtenção de informações sobre as tendências e existência de novos mercados e adequar à OP para a obtenção de uma certificação socioambiental consolidada. Evidencia-se essa situação mais nas organizações produtoras do Sul, Sudeste e nas fazendas. Frisa-se que, ainda, todas as OPs, por meio dos seus representantes, apresentaram a preocupação de desenvolver suas atividades produtivas dentro dos padrões socioambientais, independente da sua permanência na rede Fairtrade.

Outro aspecto a ser considerado, nesta pesquisa, é a contribuição do sistema Fairtrade na organização dos pequenos produtores, mesmo que para atender às exigências do sistema, mas que trouxe benefícios para os produtores que passaram a se organizar em associações ou cooperativas, como foi o caso da COODAP, COOAPAZ e a COAGROSOL. As demais organizações produtoras já estavam estruturadas, mas, mesmo assim, ao se inserirem na rede Fairtrade puderam melhor organizar suas atividades produtivas por meio dos registros e acompanhamento de suas ações administrativas.

No que diz respeito à gestão das organizações produtoras, a pesquisa revelou que há certa fragilidade na capacidade de gerir o processo de certificação Fairtrade numa perspectiva de longo prazo na maioria delas, em destaque, o atendimento às políticas de certificação FloCert e ao cumprimento dos critérios de conformidade para se manter o selo.

Esses critérios de conformidade, por exemplo o uso sustentável da água, vão evoluindo de forma gradativa a cada ano de certificação; por isso, muitas organizações produtoras acabam desistindo da certificação Fairtrade, por acharem muito complexas as exigências da empresa certificadora. Além disso, apresentaram dificuldades em elaborar e apresentar os relatórios exigidos pela FloCert, para controle das atividades desenvolvidas pelas organizações produtoras na rede.

Até organizações produtoras mais estruturadas apresentaram dificuldade em atender às demandas burocráticas da rede. Isso devido à complexidade das exigências e somada à carência de profissionais qualificados no quadro funcional da organização ou na própria região.

Ressalta-se que um processo de certificação requer que as organizações produtoras se familiarizem com as técnicas de controle da produção, isso desde o acompanhamento diário dos custos de produção ao registro dos seus trabalhadores. O relatório de controle dos custos de produção é necessário, pois contribui para a definição do preço mínimo a ser praticado, o qual nem sempre é considerado satisfatório pelo produtor, pois há situações em que o preço mínimo estabelecido pela Fairtrade International é inferior ao desejado pelo produtor; no entanto, prevalece o definido pelo sistema e o acordado, entre as partes, no ato do firmamento do contrato de compra e venda.

Quanto ao registro dos trabalhadores, essa ação é exigida com o intuito de reduzir a informalidade das relações trabalhistas. Uma das preocupações apontadas pelos representantes das OPs é a tentativa de alguns trabalhadores rurais em continuarem na informalidade, pois temem perder os seus benefícios sociais, tal como o Bolsa Família. Um dos problemas detectados, nesta pesquisa, envolvendo os trabalhadores, é mensurar a efetiva melhora de vida que o prêmio pode trazer para os mesmos, pois a maioria dos trabalhadores que atuam no campo são temporários, o que é característico na fruticultura. Desse modo, segundo representante de OPs, fica difícil detectar o impacto do prêmio, a longo prazo, na vida desses trabalhadores.

Além das organizações mencionadas acima, destaca-se a Fairtrade International, a qual, neste estudo, é considerada o centro estratégico da rede Fairtrade Frutas Frescas Brasileiras, isso porque ela coordena as transações realizadas na rede.

O termo centro estratégico foi criado por Ménard (2011) para identificar uma entidade de governo específico, que desempenha o papel de coordenadora das ações conjuntas das firmas envolvidas, de alocar as recompensas conjuntas e, além disso, tem autoridade para discipliná-las, isso em uma situação de governança híbrida, assim como foi identificado ser o tipo de coordenação exercida na rede 
estudada. Outro fator evidenciado, na rede pesquisada, e que reforça a sua caracterização como híbrida, é referente a sua constituição, a qual é composta por organizações que compartilham os seus ativos e os direitos decisórios; no entanto, a recompensa é individual (FIANI, 2013). O mesmo autor destaca que, uma das especificidades dos híbridos é a participação de agentes privados independentes, na obtenção de objetivos comuns, que requer cooperação e adaptação entre os agentes (FIANI, 2013).

O principal ativo compartilhado entre os agentes da rede Fairtrade é o de marca, pois existem investimentos altos, por parte da OP, na obtenção e manutenção da certificação e, também, pelo importador que, além de pagar o preço Fairtrade, deve pagar o prêmio à OP. Assim, há uma complementaridade entre eles, o que configura uma dependência mútua.

Os direitos de decisão são alocados em comum acordo entre as organizações produtoras e a Fairtrade International; pode-se citar, como exemplo, o fato em que as OPs permanecem totalmente responsáveis por seus próprios recursos e suas estratégias e o centro estratégico atua nas decisões relativas à evolução da marca (novos critérios de certificação, novos produtos contemplados, padrões de qualidade e estratégias de marketing) e da estrutura de governança (os contratos com as OPs e a aceitação de novos operadores ou a exclusão de operadores que já atuam na rede).

Frisa-se, também, que a Fairtrade International detém os direitos de propriedade sobre a marca e delega o seu uso pelos agentes da rede.

Quanto à recompensa obtida individualmente pelas OPs mediante a venda via Fairtrade, é oportuno destacar o prêmio Fairtrade, que é destinado ao desenvolvimento social e econômico das comunidades produtoras. Os valores dos pagamentos do prêmio são estabelecidos pela Fairtrade International, entre 5 e 30\% do preço mínimo de mercado, e não é negociável, pois ele não deve ser incluído nas negociações de vendas ou de preços Fairtrade.

O sistema Fairtrade possui como incentivos das relações contratuais o preço mínimo, o prêmio, o préfinanciamento e relações comerciais estáveis de longo prazo, os quais são definidos pela FLO e. V. Por meio da presente pesquisa, foi identificada a possibilidade de estabelecimento de relações comerciais duradouras, incentivo esse que mais atrai os produtores para a rede Fairtrade, isso porque estimula a organização dos pequenos produtores em cooperativas ou associações e proporciona um aprendizado contínuo sobre processos de gestão da produção sustentável e gestão de comercialização.
Para as organizações de maior porte, segundo o fiscal Fairtrade da Pritam Frut, o estímulo maior é aprimorar o conhecimento a respeito de uma produção sustentável, a possibilidade de atingir novos mercados internacionais. Para a técnica em meio ambiente da ECOCITRUS, além de expandir o mercado, cresce a reputação da empresa por meio da promoção de uma empresa como justa e sustentável.

A Flo-Cert é uma entidade juridicamente independente e que executa os trabalhos de certificação Fairtrade. Essa situação é ressaltada por Ménard (2011), quando ele afirma que uma das características da governança híbrida é que, para enfrentar dificuldades, as organizações podem recorrer a entidades exógenas para facilitar a coordenação e disciplina entre os parceiros. Esse papel é desempenhado pela Flo-Cert na rede Fairtrade Frutas Frescas Brasileiras. Desse modo, a FLO e. V. determina os critérios da rede e a Flo-Cert, por sua vez, monitora e controla os critérios de conformidade junto às organizações produtoras. Vale ressaltar que o selo Fairtrade é emitido pela entidade certificadora, a Flo-Cert, mas a detentora da propriedade de tal selo é a da FLO e V.

No que diz respeito às informações que estão no site da Fairtrade International e Flo-Cert, pode-se afirmar que a troca delas é controlada, essencialmente, pela Fairtrade International, desde a apresentação dos objetivos e princípios da rede à demanda de produtos no exterior. A maioria das informações sobre os critérios a serem adotados na produção das frutas Fairtrade são compartilhadas via Internet, a exemplo, dos critérios gerais e específicos de produtos, bem como as políticas e procedimentos de certificação da Flo-Cert. Tal meio de informação tem sido alvo de queixas por parte da maioria dos representantes das OPs, pois, segundo os entrevistados, isso dificulta o acesso às informações, porque não são todos os produtores que dominam essa ferramenta de comunicação. Outro aspecto que tem sido debatido entre os agentes e estudiosos sobre o movimento Fair Trade é referente ao público alvo do sistema Fairtrade, pois, além de contemplar as organizações produtoras formadas por pequenos produtores, também, atende as fazendas. A inclusão das fazendas ocorreu em 1994, com o intuito de beneficiar trabalhadores que, assim como os pequenos produtores, precisam de apoio para melhorar suas condições de vida e de trabalho, bem como trazer melhorias para sua comunidade. Outro motivo para a inserção das fazendas, de acordo com os entrevistados da Fairtrade International, é que os produtores não têm condições de atender à crescente demanda do mercado 
Fairtrade e que a entrada de grandes empresas privadas pode abrir novos mercados, os quais poderiam favorecer os pequenos produtores. Tal inclusão foi apresentada, por seis representantes de organizações produtoras, como uma errônea decisão da Fairtrade International, pois a entrada das empresas agrícolas tem provocado impacto negativo na reputação do sistema Fairtrade e se contradiz com a verdadeira identidade do movimento. Segundo coordenador da Gestão e Incidência da Coordinadora Latinoamericana y del Caribe de Comercio Justo (CLAC): A CLAC não apoia a certificação de grandes empresas, ao ponto de, em 2006, criar um selo denominado de "Símbolo de Pequenos Produtores" para sinalizar ao consumidor a origem (OPP ou fazendas) dos produtos Fairtrade. Essa iniciativa, por sua vez configura-se numa tentativa de inibir a atuação da Fairtrade International em certificar as fazendas, o que para a CLAC prejudica os pequenos produtores. Além disso, 05 (cinco) dos representantes de OPs entrevistados declararam não estar satisfeitos com a entrada de grandes cooperativas na rede, mesmo que essa sejam formadas por pequenos produtores. Por isso, um grupo de produtores de frutas frescas tem questionado a transparência nas ações e decisões tomadas pela Fairtrade International. Enfim, à luz do que foi apresentado no decorrer deste estudo, é possível afirmar que todas as transações são iniciadas, negociadas, monitoradas e, até mesmo, terminadas sob a coordenação da Fairtrade International.

\subsubsection{Contratos existentes entre os agentes da rede Fairtrade Frutas Frescas Brasileiras}

A coordenação da Fairtrade International é emoldurada por contratos do tipo formal, os quais se referem aos contratos de certificação firmados entre o produtor e os demais operadores certificados da rede Fairtrade e a Flo-Cert. Esses são determinados de maneira intencional e objetiva pela Fairtrade International.

Também foi possível identificar a importância dos mecanismos formais estabelecidos pela rede Fairtrade, os quais são os contratos neoclássicos existentes na rede, em que os termos das trocas são claros e não tão abertos como os termos dos contratos relacionais.

Quanto ao caráter do contrato, a pesquisa apontou que os contratos firmados entre a certificadora e as organizações produtoras são de adesão, tidos pelo Direito como de massa, com cláusulas preestabelecidas pela Fairtrade International. A Flo-Cert, por meio de mecanismos de controle, verifica se os critérios de conformidade estão sendo seguidos pelos produtores para, a partir daí, analisar a viabilidade de concessão ou de renovação da certificação. $\mathrm{O}$ monitoramento possui como referências as Normas Genéricas Fairtrade para Organizações de Pequenos Produtores, e os Critérios Gerais de Comércio e todas as normas específicas das frutas frescas para as situações de trabalho contratado. Também é utilizado pela Flo-Cert a ISO 65, a qual consiste em um sistema de credenciamento de representatividade no mercado mundial de certificação de produtos agropecuários. Caso seja identificado o não cumprimento de algum critério preestabelecido pela Flo-Cert, a OP não estará mais autorizada a utilizar a marca Fairtrade e, com isso, não poderá comercializar seus produtos na rede.

Segundo os entrevistados das OPs, não há espaço para discutir as cláusulas contratuais, quaisquer que sejam, salvo questões de data de vencimento ou algumas cláusulas específicas que não alteram a substância do negócio, tais como as exigências específicas voltadas para o produto a ser comercializado.

Desse modo, há uma aparente "imposição de vontade", cabendo às organizações apenas aderirem ou não ao sistema Fairtrade. Isso provoca a despersonalização das relações contratuais, pois são dirigidas a todos aderentes indistintamente, visando simplificar e otimizar as relações comerciais e econômicas (SCHMITT, 2006; GALLO, 2009).

Quanto aos contratos firmados entre as organizações produtoras e os compradores, são paritários. As partes, a princípio, negociam uma com a outra e, principalmente, conhecem o contrato por inteiro ao ponto de discutir suas cláusulas. Na rede Fairtrade Frutas Frescas Brasileiras, esse papel, na maioria dos casos, é desempenhado pelo trader ou entidade de apoio.

As organizações produtoras, que já celebraram contratos junto aos importadores na rede Fairtrade, são: a COODAP, Pritam Frut, Associação Manga Brasil e Associação dos Pequenos Produtores do Núcleo 06. Dessas organizações, apenas a Pritam Frut continua comercializando seus produtos na rede e as demais saíram pelos seguintes motivos: preços do mercado interno mais atrativos; falta uma compreensão maior por parte dos cooperados, o que vem a ser, na prática o Cooperativismo e, principalmente, a ausência de demanda por parte dos importadores. É unânime a declaração dos entrevistados das organizações produtoras que a crise econômica, desde 2008, na Europa, afetou as relações comerciais na rede.

Outro tipo de contrato identificado na pesquisa, que envolve as organizações produtoras na rede é o firmado com os traders. Como já mencionado, anteriormente, 
a presença dos traders é muito forte na rede Fairtrade Frutas Frescas Brasileiras, pois, segundo os representantes das organizações produtoras, a atuação deles facilita as transações comerciais junto aos importadores. Esse tipo de contrato é o que mais se aproxima dos relacionais, pois os produtores buscam confiar nos traders, já que eles são um elo importante entre as organizações produtoras e os importadores. Em alguns casos, a ausência do trader, no campo das negociações, provocou o desligamento de OPs da rede. Isso porque o trader ficava responsável pela identificação de novos compradores e, além disso, por todo o processo de negociação entre a OP e o importador. Lembra-se que os compradores são internacionais e se comunicam em outros idiomas e, pelo fato de as OPs não possuírem tradutores, com a ausência do trader o fechamento do contrato seria inviabilizado.

Os três contratos identificados na pesquisa, e explicitados acima, são do tipo neoclássicos, pois as transações tendem a ser de longo prazo, e a variável incerteza é relevante. Outra característica marcante é a presença de uma terceira parte para resolver disputas e avaliar o desempenho estipulado pelo contrato no momento posterior à firmação contratual. Além disso, os contratos mencionados apresentam quatro características que, segundo Menárd (1996, p. 158), devem ser observadas em contratos neoclássicos, as quais identificadas nos contratos Fairtrade Frutas Frescas Brasileiras: apresentam mecanismos de adaptação; fornecem zona de tolerância dentro da qual desequilíbrios podem ser ajustados; há um esforço no compartilhamento das informações e, principalmente, há a arbitragem em lugar dos litígios. Todos esses mecanismos contratuais são estruturados e coordenados pela Fairtrade International, por meio de uma autoridade delegada pelos agentes envolvidos na rede. De acordo com as considerações acima apresentadas, em que a Fairtrade International é uma instituição de governança na rede Fairtrade, pois opera no monitoramento e controle das transações existentes na referida rede, conclui-se que a relação que surge nas transações contratuais é considerada de dependência trilateral. De acordo com Williamson (2012), uma forma institucional intermediária se torna evidentemente necessária, dados os limites do direito contratual clássico para sustentar tais transações e o custo proibitivo da governança (bilateral) da transação específica. A Figura 1, a seguir, resume as características dos contratos identificados na rede Fairtrade frutas Frescas brasileiras.

Após a adesão à rede, as OPs devem celebrar contrato com a Flo-Cert para firmar os termos previamente estabelecidos pela Fairtrade International. Destaca-se que as condições contratuais do contrato de certificação apresentadas aos produtores de frutas são preestabelecidas, uniformes e unilaterais, ou seja, não foram redigidas pela coletividade negocial. Nesse contexto, resta ao produtor decidir se ele adere ou recusa os termos contratuais impostos pelo centro estratégico, por meio da certificadora da rede.

\begin{tabular}{|c|c|c|c|}
\hline Contratos & $\begin{array}{c}\text { Quanto } \\
\text { à formação }\end{array}$ & Frequência & $\begin{array}{c}\text { Tipo } \\
\text { do contrato }\end{array}$ \\
\hline Certificação & Adesão & Discreta & $\begin{array}{c}\text { Trilateral } \\
\text { Neoclássico }\end{array}$ \\
\hline Trader & Paritário & Discreta & $\begin{array}{c}\text { Trilateral } \\
\text { Neoclássico }\end{array}$ \\
\hline Comprador & Paritário & Discreta & $\begin{array}{c}\text { Trilateral } \\
\text { Neoclássico }\end{array}$ \\
\hline
\end{tabular}

FIGURA 1 - Características dos contratos existentes entre as organizações produtoras e os demais agentes da rede Fairtrade Frutas Frescas Brasileiras

Fonte: Elaborado pelos autores

Quanto à frequência, os três contratos formais apresentados são classificados como discreta, pois esses são supervisionados até a sua efetivação pela Fairtrade International e, por isso, estabelece comprometimento entre as partes envolvidas.

\section{CONCLUSÕES}

Conclui-se que o desempenho esperado decorrente da aplicação dos princípios fundamentais do Fairtrade depende fundamentalmente da continuidade dos contratos, pois o sistema, em seus objetivos, prima pelas relações duradouras, em especial, entre produtores e compradores, para que, dessa forma, se obtenham os bons resultados esperados pelo sistema. No entanto, as evidências explicitadas nesta pesquisa indicam que, na prática, pelo menos no que foi configurado na rede Fairtrade Frutas Frescas Brasileiras, a Fairtrade Internaticional, por meio de suas ações, tem priorizado o atendimento de critérios de conformidade por parte dos produtores, em detrimento do fortalecimento das relações pessoais destes na rede, ao ponto de a maioria dos representantes das OPs entrevistados, apenas relatar os contatos com a Flo-Cert. Essa situação vem afetando a confiança, a reputação e, em especial, a continuidade dos contratos. 
Muitas foram as dificuldades encontradas durante a realização desta pesquisa, em especial, o acesso às informações internas das organizações pesquisadas.

No que diz respeito às organizações produtoras, aquelas formadas por associações ou cooperativas com origem em regiões distantes, como no interior das Regiões Norte e Nordeste, carecem de uma melhor estrutura de gestão documental. Isso resultou na ausência de registros contratuais e a organização documental das transações realizadas junto à Fairtrade International, o que corresponde à maioria das organizações de produtores, $\mathrm{o}$ que dificultou o acesso e a análise de contratos firmados na rede Fairtrade Frutas Frescas Brasileiras. Além disso, algumas das organizações produtoras, até o momento da pesquisa, ainda, não tinham realizado nenhuma venda de suas frutas na rede Fairtrade, impossibilitando a análise contratual entre produtores e compradores. Em relação à coleta de dados junto aos demais agentes da rede, os pesquisadores encontraram limitações para o fornecimento de dados referentes à comercialização dos produtos, tais como o preço praticado e o volume comercializado na rede. Registra-se, igualmente, dificuldade no acesso aos relatórios de conformidade da Flo-Cert.

A partir dos resultados foi possível identificar a necessidade de uma maior interação entre a FLO e os agricultores das OPs, uma maior comunicação entre os agentes da rede e que a Flo-Cert promova capacitações sobre os critérios de conformidade. Desse modo, a permanência das OPs na rede poderia ser ampliada.

Quanto às sugestões de pesquisas futuras, recomenda-se a realização de outros estudos a partir de uma amostra mais abrangente, que inclua entrevistas com mais representantes da Fairtrade International, da Flo-Cert, distribuidores e compradores internacionais, com o intuito de compreender as relações contratuais em toda a rede Fairtrade Frutas Frescas Brasileiras.

\section{AGRADECIMENTO}

Ao Instituto Federal do Sertão Pernambucano (IF SERTÃO -PE) pelo apoio financeiro, o qual foi essencial para a realização dessa pesquisa.

\section{REFERÊNCIAS}

AZEVEDO, P. F. Níveis Analíticos. In: COMPETITIVIDADE, Mercado, Estado e Organizações. São Paulo: Singular, 1997. p. 53-70.
BALESTRIN, A.; ARBAGE, A. P. A perspectiva dos custos de transação na formação de redes de cooperação. RAE eletrônica, São Paulo, v. 6, n. 1, 2007. Disponível em: $<$ https://www.scielo.br/pdf/raeel/v6n1/a08v6n1.pdf $>$. Acesso em 24 out. 2020.

BOUROULLEC, M. D. M. Governanças Hibridas no Comércio Justo Citrícola entre o Brasil e a Europa: arranjos institucionais complementares aos contratos. 2010. 219 f. Tese (Doutorado em Engenharia de Produção) - Universidade Federal de São Carlos, São Carlos, 2010.

BRASIL. Ministério da Agricultura, Pecuária e Abastecimento. AGROSTAT - Estatísticas de Comércio Exterior do Agronegócio Brasileiro. Exportação e Importação. Disponível em: $<$ http://indicadores.agricultura. gov.br/agrostat/index.htm> Acesso em 20 nov. 2020.

CANDELA, R. A. The Role of Transaction Costs in Douglass North's Understanding of the Process of Change in Economic History. In A. Marroquín; N. Wenzel (Eds.), A companion to Douglass North. Guatemala City: Universidad Francisco Marroquín. Available at SSRN. Disponível: <https://papers.ssrn.com/sol3/papers. cfm?abstract_id=3282751 > Acesso em: 20 out.2020.

CARIO, S. A. F.; NICOLAU, J. A. Estrutura e padrão de governança em arranjos produtivos locais no Brasil: um estudo empírico. Ensaios FEE, Porto Alegre, v. 33, n. 1, p. 177-206, maio 2012.

CARVAlHO, M. S. de. Contratos formais entre empresas processadoras de laranja e citricultores: um estudo de múltiplos casos entre os anos-safras de 1978/79 a 2011/12 na perspectiva dos produtores. 2015. $258 \mathrm{f}$. Tese (Doutorado em Engenharia de Produção) - Programa de Pós-Graduação em Engenharia de Produção, Universidade Federal de São Carlos-UFSCar, São Carlos, 2015.

CLAC. O que é a CLAC? Disponível em: $<$ http://claccomerciojusto.org/pt-br/clac/presentacion/quem-somos/>. Acesso em: 20 out.2020.

COMISSÃO DAS COMUNIDADES EUROPEIAS. Comunicação da comissão ao parlamento europeu, ao conselho e ao comité económico e social europeu: comércio, crescimento e desenvolvimento: Adaptar a política de comércio e investimento aos países mais necessitados. Bruxelas: COM, 2012. 
COOK, M. L; KLEIN, P. G.; IllOPOUlOS, C. Contracting and organization in food and agriculture. In: NEW Institutional Economics: a guidebook. New York: Cambridge University Press, 2008.

FAIRTRADE INTERNATIONAL. A Charter of Fair Trade Principles. 2009. Disponível em: $<$ http://www. fairtrade.net/fileadmin/user_upload/content/2009/about us/documents/Fair_Trade_Charter.pdf $>$. Acesso em: 15 mar. 2010.

. Choosing a fairer future through trade. Annual report 2018-2019.2019a Disponível em: <https://files. fairtrade.net/publications/2018-19_FI_AnnualReport. pdf>. Acesso em: 05 nov. 2020.

. Monitoring the of fairtrade: overall: monitoring report 10th edition. 2019b. Disponível em: <https:// files.fairtrade.net/publications/2019_Monitoring_ summary_10thEd.pdf $>$. Acesso em: 05 nov. 2020.

. Strong Producers, Strong Future. Annual report 2013-2014. 2014a. Disponível em:<http://www.fairtrade. net/fileadmin/user_upload/content/2009/resources/201314_AnnualReport_FairtradeIntl_web.pdf $>$. Acesso em: 28 dez. 2014.

FAO. Boletín de agricultura familiar de América Latina y el Caribe. 2012. Disponível em: $<$ http://www. fao.org/docrep/019/as191s/as191s.pdf>. Acesso em: 24 mar. 2014.

FIANI, R. Arranjos institucionais e desenvolvimento: o papel da coordenação em estruturas híbridas. Brasília: IPEA, 2013.

FLO CERT. Certificação: procedimento operacional padrão. 2014a.. Disponível em: <http://www.flocert.net/ wp-content/uploads/2014/02/CERT-Certification-SOP-29pt.pdf $>$. Acesso em: 05 jun. 2013.

FURUBOTN, E.; RICHTER, R. The New Institucional Economics: an assessmen. In:

. The New Intitucional Economics. Texas: A\&M Press, 1994.

GALlO, J. A. A. Abordagem Teórica sobre a Eficácia dos Contratos de Longo Prazo. 2009. Disponível em:<http://www.revistadir.mcampos.
br/PRODUCA OCIENTIFICA/artigos/jos ealb ertoalbenygalloartigocontratosdelongoprazo.pdf $>$. Acesso em: 08 jun. 2012.

GRADL, C. et al. Growing Business with smallholders: a guide to inclusive agribusiness. 2012. Disponível em: <http://www.agribusiness-withsmallholders.net/ fileadmin/user_upload/publications/GuideGrowing Business_with_Smallholders_large.pdf $>$. Acesso em: 25 nov. 2012 .

GRASSI, R. A. Cooperação interfirmas, "reféns" e "sombra do futuro": Em busca de uma integração teórica a partir de Williamson. Economia Aplicada, São Paulo, v. 8, n.1, 2004.

Williamson e formas híbridas: uma proposta de

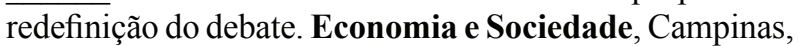
v. 12, n. 1, jan. /jun., 2003.

GROVER, V.; MALHOTRA, M. K. Transaction cost framework in operations and supply chain management research: theory and measurement. Journal of Operations Management, Washington, v. 21, n. 4, p. 457-473, 2003.

HENDRIKSEN, E. S.; VAN BREDA, M. F. Teoria da contabilidade. São Paulo: Atlas, 1999.

JOHN, G.; WEITZ, B. A. Forward Integration into Distribution: An Empirical Test of Transaction Cost Analysis. Journal of Law, Economics, and Organization, Oxford, v. 4, n.2, p. 337-355, 1988.

KUhlmann, M. O que é Comércio Justo? uma introdução à certificação de comércio justo. Bonn, Alemanha: Fair Trade Labelling Organizations Internacional, 2006. Disponível e m : < http: // w w w fairtrade.net/uploads/ media/_Comercio_Justo_Modulo_1_O_que_e_ Comercio_Justo.pdf $>$ - Acesso em: 04 abr. 2012.

MACNEIL, I. R. Contracts: Exchange Transactions and Relations. Northwestern University Law Review, Chicago, v. 72, p. 854-905, 1978.

MELlo, F. O. T. de; PAUlillo, L. F. Análise do alinhamento entre os atributos das transações e as formas de governanças empregadas na citricultura. Gestão e Produção, v. 16, n. 4, 2009. 
MÉNARD, C. On Clusters, Hybrids and other Strange Forms: The Case of the French Poultry Industry. Journal of Institutional and Theoretical Economics, Tubingen, v. 152, n. 1, p.154-183, 1996.

Hybrid modes of organization: alliances, joint ventures, networks, and other "strange" animals. Paris: Université Paris, 2011. Disponível em: <http://halshs. archivesouvertes.fr/halshs-00624291/>. Acesso em: 12 nov. 2013.

MULLANEY, L. Seven tops trends for the food industry in 2013. Disponível em: <http:/www.foodmanufacture.co.uk/Business-News/ Seven-top-trends-for-the-food-industryin-2013.

NICOLAU, J. A. Análise das Estruturas Organizacionais Existentes na Cadeia Agroindustrial. Textos de Economia, Florianopolis, v. 5, n. 1, p. 7-21, 1994.

NORTH, D. C. Structure and Change in Economic History. New York: WW Norton, 1981.

PEDINI, S. Fair Trade: alternativa ao mercado convencional de café e processos de empoderamento de cafeicultores familiares. 2011.174 f. Tese (Doutorado) Universidade Federal de Larvas, Larvas, 2011.

RAMOS, N. P.; FERRAZ, J. M. G. Certificação Socioambiental. Disponível em: $<$ http:// www.agencia.cnptia.embrapa.br/gestor/ c a n a - d e - a c u c a r / a rvore / C ON TA G $01{ }_{-}{ }_{4}$ 711200516715.html.>. Acesso em: 20 jan. 2013.

SANTOS, S. R. S. A nova economia institucional. 2010. Disponível em: $<\mathrm{http}: / / \mathrm{d}$. yimg.com/kq/groups/16643321/270946459/name/ $\mathrm{A}+$ nova+economia + institucional.pdf $>$. Acesso em: 14 dez. 2012.

SCHMITT, C. H. Cláusulas abusivas nas relações de consumo. Revista dos Tribunais, São Paulo, p. 72, 2006.

SCHNEIDER, J. Relatório da Pesquisa Mundial de Comércio Justo: parte 1. Brasília: SEBRAE, 2012.

SILVA, L. X. da. Análise do Complexo Agroindustrial Fumageiro Sul-brasileiro sob o enfoque da Economia dos Custos de Transação. 2002. 280 f. Tese (Doutorado em Economia) - Programa de Pós-Graduação em Economia, Faculdade de Ciências Econômicas, Universidade Federal do Rio Grande do Sul, Porto Alegre, UFRGS, 2002.

SIMON, H. The Architecture of complexity. Proceedings of the American Philosophical Society, Philadelphia, $\mathrm{n}$. 106, p. 467-482, Dec. 1962.

VIANA, M. M.; JULIÃO, L. Certificação Socioambiental: a nova geração das boas práticas na fruticultura. CEPEA, São Paulo, n. 99, p. 8-17, mar 2011.

WILLIAMSON, O. Transaction-cost economics: the governance of contractual relations. The Journal of Law and Economics, Chicago, v. 22, n. 2, p. 239-261, 1979.

. The Economic Institutions of Capitalism:

Firms, Markets, Relational Contracting. New York: The Free Press, 1985.

Economic organization: firms, markets and policy control. New York: New York University Press, 1986.

Transaction Cost Economics. In: HANDBOOK of Industrial Organization. Netherlands: Elsevier Science Publ, 1989.

- Comparative Economic Organization: The Analysis of Discrete Structural Alternatives. Administrative Science Quarterly, Ithaca, v. 36, p. 269-296, 1991.

. Transaction Cost Economics and Organization Theory. Industrial and Corporate Change, Oxford, v. 2, p. 107-156, 1993.

- Calculativeness, trust and economic organization. In: W I L L I A M S O N, O. Mechanisms of governance. Uk: Oxford University Press, 1996.

As instituições econômicas do capitalismo: firmas, mercados e relações contratuais. São Paulo: Pezco Editora, 2012.

YIN, R. K. Estudo de caso: planejamento e métodos. Porto Alegre: Bookman, 2005. 3ed. 212p. 
ZYLBERSZTAJN, D. Estruturas de Governança e Coordenação do Agribusiness: Uma Aplicação da Nova Economia das Instituições. 1995. Tese (Livre Docência)Universidade de São Paulo, São Paulo, 1995.
Conceitos gerais, evolução e apresentação do sistema agroindustrial: economia e gestão dos negócios agroalimentares. São Paulo: Pioneira, 2000 . 